Research Journal of Biological Sciences 5 (1): 9-12, 2010

ISSN: $1815-8846$

(C) Medwell Journals, 2010

\title{
Clinical Reports of Carbadox Toxicity in Mexican Swine Farms
}

\author{
${ }^{1}$ Ramiro Ramírez Necoechea, ${ }^{2}$ Guillermo Davalos Aranda, ${ }^{2}$ Jose Antonio Salinas Melendez, \\ ${ }^{2}$ Juan Jose Zarate Ramos, ${ }^{3}$ Jose Francisco Hernandez Ramírez and \\ ${ }^{1}$ María de Lourdes Alonso Spilsbury \\ ${ }^{1}$ Departamento de Producción Agrícola y Animal, Universidad Autonoma Metropolitana-Xochimilco, \\ México, Calzada del Hueso 1100, Col. Villa Quietud, Delegación Coyoacán, C.P. 04960, Mexico \\ ${ }^{2}$ Facultad de Medicina Veterinaria y Zootecnia, Universidad Autónoma de Nuevo León, \\ Francisco Villa s/n Ex Hacienda EL Canada, General Escobedo, Nuevo León, C.P. 66050, México \\ ${ }^{3}$ Facultad de Estudios Superiores Zaragoza, UNAM, \\ Batalla 5 de mayo s/n Esq. Fuerte de Loreto, Col. Ejército de Oriente, Mexico
}

\begin{abstract}
The researchers describe several cases of carbadox toxicity recorded during 30 years of Mexican swine practice by a panoramic overview focused in clinical manifestations. After describing the doses and methods of using carbadox either following or not the manufacturer recommendations, the researchers bring up five carbadox toxicity cases pointing out the most striking clinical signs such as growth delay, jaundice, ear, tail and flank biting, urine drinking, among others. We offer a pathway of carbadox toxicity in weaned and growing pigs as well as a clinical carbadox toxicity scale (Neco scale) for early clinical carbadox toxicity detection.
\end{abstract}

$\underline{\text { Key words: Carbadox toxicity, clinical signs, pigs, ear biting, tail biting, flank biting, urine drinkers, Jaundice }}$

\section{INTRODUCTION}

Carbadox is a member of the family of synthetic organic compounds classified as quinoxaline-di $\mathrm{N}$ oxides. It's used as a growth promoter and a control for pig dysentery and bacterial enteritis (Straw et al., 1999).

It has been used for years by the high tech swine industry all over the world. However, in some countries there's no official limitations regarding his use in pigs that's why the use of carbadox by farmers is quite common particularly in México. This under regulated handling of the drug has produced some spectacular cases of carbadox toxicosis in the Mexican swine industry.

The aim of this report is to get the swine farmers attention over the many repercutions of misunderstanding the way in which carbadox can be used particularly the Chinese bulky carbadox (available in the Mexican pharmaceutical market) which comes ready to be used without prescription information and by cost is the first choice of Mexican farmers.

Carbadox has been recommended at the dose of $55 \mathrm{ppm}$ to prevent swine dysentery and as a growth promoter agent (Thrasher et al., 1969). Some farmers used it at higher levels of $165 \mathrm{ppm}$ in sows to eradicate the disease from the herd. In Mexico it is used from a few weeks after weaning until the age of about 14 weeks. After weaning the drug is especially administered to prevent post weaning diarrhea and oedema disease in the first week of fattening.

It is widely used in the prevention of swine dysentery (Doyle Dysentery) (Straw et al., 1999). For preventive $(50-55 \mathrm{ppm})$ and msometimes therapeutic (100-150 ppm) purposes carbadox is given as medicated feed during 3-4 weeks or even longer, if necessary.

In different countries carbadox is also used as a feed-additive to promote animal growth (Thrasher et al., 1969; Yen et al., 1976).

The legally allowed dosage in the European Community is $50 \mathrm{ppm}$. A few years after its introduction to the veterinary pharmaceutical market, carbadox was found guilty of inducing toxic effects in weaned pigs. However, it was difficult to distinguish clinically between carbadox intoxication, Estereotipias orostenicas and the chronic stage of some intestinal disorders like postweaning diarrhea.

The most important clinical signs were growth retardation, wasting, urine drinking and a strong interest in salt containing products. From earlier studies (Van Der Molen et al., 1985), it appeared that carbadox

Corresponding Author: Ramiro Ramírez Necoechea, Resina no. 282 int. 401, Col. Granjas Mexico D.F. C.P. 08400, Mexico 
could include a similar clinical picture to that seen in the field associated with specific histological changes in the adrenal (Ramírez et al., 2010).

These histological changes gave us a tool to differentiate between carbadox intoxication and the gastrointestinal disorders mentioned and the orostenic syndrome in carbadox free animals.

From clinical reports, it was apparent that carbadox intoxication occurred frequently in veterinary practice (Sidoli et al., 1992), often with economic losses as an effect of growth retardation due to water unbalance in turn due to circulatory aldosterone shortage. This reduction in plasma aldosterone occurred even before signs of toxicity began, the changes in serum, sodium and potassium levels appear to be a better indication of impending toxicity than plasma aldosterone levels, since they occur around the time that toxicity symptoms become apparent (Van Der Molen et al., 1985).

Carbadox and olaquindox are chemically related and have a similar mechanism of toxicity (Baars et al., 1988). These researchers found that after 6 weeks inclusion in the feed at $100 \mathrm{mg} \mathrm{kg}^{-1}$, olaquindox and carbadox induced similar changes to the zona glomerulosa of the adrenal cortex. They also observed urine drinking in the olaquindox trial group at $50 \mathrm{mg} \mathrm{kg}^{-1}$ in the feed.

\section{MATERIALS AND METHODS}

Over the years, the researchers recorded several cases of carbadox toxicity in the swine practice in México. All of them shown different grades of clinical signs. From them, we selected some that we believed could be useful for vets in practice.

The standard approach in all those cases was a panoramic clinical overview, a collection of relevant clinical data, postmortem examination if available, gross microscopic pathology description focused in adrenal histological changes such as atrophy of zona glomerulosa with hydropic degeneration and necrosis of the remaining cells.

Case 1: reproductive efect of carbadox: A farrow to finish farm shown a violent outbreak of dysentery. Carbadox was added to all feeds on the farm at $55 \mathrm{ppm}$ except for the gestation feed which was medicated at a dosage of $180 \mathrm{ppm}$ (intended as eradication schedule) (Henry, 1981). The treatment was suspended at 45 days due to reproductive failure. Table 1 shows the performance of the herd before during and after the medication period. The females looked healthy, came in heat normally after
Table 1: Reproductive performance of sows and gilts before during and after the medication with carbadox (weekly average data)

\begin{tabular}{|c|c|c|c|}
\hline Parameters & $\begin{array}{l}6 \text { months } \\
\text { before } \\
\text { medication }\end{array}$ & $\begin{array}{c}\text { During } \\
\text { Medication } \\
\text { period }\end{array}$ & $\begin{array}{l}6 \text { months } \\
\text { after } \\
\text { medication }\end{array}$ \\
\hline Farrowings weekly & 40 & $22^{*}$ & 40 \\
\hline Born alive $\mathrm{L}^{-1}$ & 10 & $9^{*}$ & 10 \\
\hline Born dead $\mathrm{L}^{-1}$ & 1 & 2.0 & 0.8 \\
\hline Conception rate & $>85$ & $<15 \%$ & $>84 \%$ \\
\hline
\end{tabular}

*Sow and gilts that farrowed after the medication period but were mated during the medication period

weaning and failed to get pregnant. Most of the returns were regular (18-24 days after mating or multiple of this). During medication many sows did not conceive to services of 2 successive heat periods. The conception rate returned to normal 1 week or 2 after carbadox withdrawal. A quite similar picture was reported in other studies (Desrosiers et al., 1988).

Case 2: combined carbadox and furazolidone toxicity: The clinical symptoms were lack of appetite, weakness, reduced growth, dehydration, urine drinking and constipation in pigs ranging from 10-18 weeks of age in a 1200 sow farrow to finish farm. Signs were present after feed medication with 100-600 ppm of carbadox and $200 \mathrm{ppm}$ of furazolidone during a period of 4-10 weeks. The clinical and pathological findings obtained in the present study were similar to those previously described as associated with consumption of high levels of carbadox (Power et al., 1989) alone or in combination with furazolidone (Sogbe et al., 1994). Potentiation of the toxic effect of carbadox by furazolidone in pigs has been described before. It's been suggested that the potentiating effect of furazolidone is associated with enhancement of the uptake of carbadox from the intestine (Jager and Vromeen, 1990).

Case 3: orostenic syndrome tail ear biting: Signs began approximately 3 weeks following the introduction of the diet containing $100 \mathrm{mg} \mathrm{kg}^{-1}$ of carbadox to fattening pigs. Growth rate reduction was noticed 6 weeks later with the result that no pigs were fit for sale at the expected time. Piglet quality at weaning was good but 3 weeks later were in variable body conditions some appeared normal while others were unthrifty and had a contracted abdomen. Body condition in the older pigs showed a different grade of emaciation. Feed intake was reduced $>50 \%$. There was a high incidence of tail biting, ear biting and occasional case of flank biting. They were constipated with faeces with appearance of sheep droppings. Pigs were restless, urine licking from the floor and from urinating penmates was present. There was no increase in mortality levels in 
the affected group. Appetite improved immediately following the carbadox withdrawn. With the exception of highly unthrifty pigs the remainder of them took 6-8 weeks more to be ready for sale.

Case 4: urine drinking, jaundice caudofagia and marketing delay: A group of fattening pigs (40 kg weight average) received $150-180 \mathrm{ppm}$ of carbadox during 20 days. The clinical signs shown by those animals were dry faeces increased water consumption, anorexia, unthrifty hyperactive animals, loss of body condition, caudofagia and ear biting, urine drinking from the floor and from penmates, decreased abdominal volume, pale skin jaundice, long withered hair. Carbadox withdrawn allows the recovery of pigs between 8-10 weeks later however they reach the market weight 8 weeks after the usually farm time.

Case 5: uncoordination, perverted eating, shivering and loss of eight: A farrow to finish farm with increased fattening mortality and growing retardation. With history of multiple outbreaks of tail and ear biting (was primary diagnosed as a mineral deficiency) as well with recurrent episodes of swine dysentery in order to control them 140 ppm of carbadox was added to feed during 6 weeks. Afterward in the fattening period, 70 ppm of carbadox was used combined with dimetredazol tylan phosphate fluorfenicol and tiamulin due to continuous dysentery signs and growing retardation. That sort of plurimedicate approach lasted 8 months. Time during which many different clinical sings were recorded. Among them the most striking were uncoordination of the hind legs, sway back, ataxia, muscular tremors (Shivering) dry faeces, urine drinking from the floor and from the penmate prepuce at urinating time, irritability, unthrifty animals, dry pale skin, perverted eating and intensive licking of the pen wall to the point of make some wall perforations (holes). Eating door paint and cleaning devices, (brushes and brooms) (Sidoli et al., 1992). Pigs showed dehydration, hemorrhagic gastritis and ulceration of mucosa, bronchopneumonia, hydrothorax, hydropericardium. The most significant lesions were atrophy of zona glomerulosa in the adrenals with hydropic degeneration and necrosis of the remaining cells (Ramírez et al., 2010).

\section{RESULTS AND DISCUSSION}

Carbadox has a particularly narrow safety margin, the normal recommended inclusion rate is $50 \mathrm{gms}$ per tonne, the use of $100 \mathrm{~g} \mathrm{ton}^{-1}$ can produce toxicity when included in a diet for over 3 weeks. In this case, the clinical signs started as reduced growth rates reduced abdominal volume, constipation, ear biting, unthrifty, tail and flank biting. Besides severe water metabolic imbalances as it's shown in Fig 1.

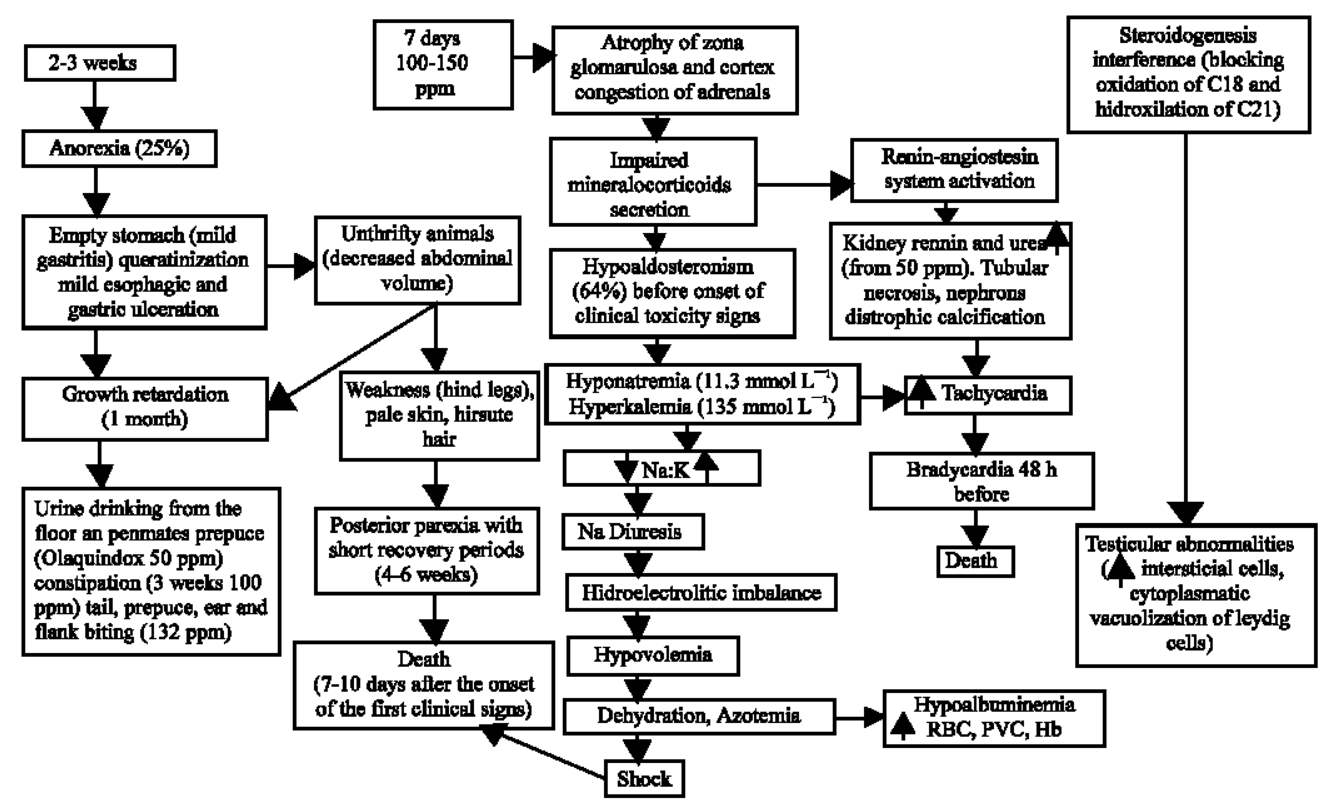

Fig 1: Pathway of carbadox toxicity in weaned and growing pigs after accidental ministration of high dose of carbadox $100-800$ ppm in feed single or furazolidone combined 


\section{CONCLUSION}

The variety of clinical signs and concomitant circumstances found in the different type of recorded cases, drive our attention to the following most striking signs in the presence of which could give us the early suspicious of carbadox toxicity:

- Dry faeces

- Urine drinking

- Outbreaks of tail and ear biting

- Intense thirst

- Prepuce and flank suckling in weaners

- Reproductive failure in carbadox medicated sows

- Growth retardation with constipation (sheep droppings )

- Decreased abdominal volume

- Uncoordinated walking

- Shivering

- Perverted eating

- Licking of the pen walls and pen furniture

- Use of recommended carbadox doses combined with additive drugs that compete with the same detoxication metabolic pathways of carbadox

Finally as clinical aid we developed the Neco's carbadox toxicity scale (Nabuurs et al., 1990) as follow:

Dose and time required to show the two initial signs of carbadox toxicity (Dry faeces and thirst)

\begin{tabular}{lc}
\hline Dose $(\mathrm{ppm})$ & Time (days) \\
200 & 14 \\
150 & 21 \\
100 & 28 \\
\hline
\end{tabular}

\section{REFERENCES}

Baars, A.J., E.J. van der Molen, T.J. Spierenburg, G.J. de Graaf, M.J.A. Nabuurs and L.P. Pager, 1988. Comparative toxicity of three quinoxaline-di-Ndioxide feed additives in young pigs. Arch. Toxicol., 12: 405-409.

Desrosier, R., R. Sauvageau and M. Beauregard, 1988. Carbadox and procaine penicillin toxicity in pigs. Proceedings of the 10th International Pig Veterinary Society Congress, (IPVSC'88), Rio de Janeiro Brasil, pp: 249-249.
Henry, S.C., 1981. Control of swine dysentery. Proceedings of the 29th Pfizer Annual Research Conference, May 19, St. Louis, pp: 131-142.

Jager, L.P. and L.H. Vromeen, 1990. Toxicological considerations in the evaluation in the evaluation of Veterinary drugs. Tijdschr Diergeneeskd, 155: 727-735.

Nabuurs, M.J.A., E.J. Van Der Molen, G.J. de Graaf and L.P. Jager, 1990. Clinical signs and performance of pigs treated with different doses of carbadox, cyadox and olaquindox. J. Vet. Med. A., 37: 68-76.

Power, S.B., W.J.C.D. McLaughlin, M.C. Walsh and M.F. Dromey, 1989. Accidental carbadox overdosage in an Irish weaner-producing herd. Vet. Rec., 124: $367-370$.

Ramírez, N.R., G.A.R. Nevarez, T.L.E. Rodriguez, A.G. Davalos, R.J.F. Hernández and R.R. Ramirez, 2010. Carbadox intoxication in Pigs. J. Anim. Vet. Adv., 9: $85-87$.

Sidoli, L., P. Candotti, G. Barigazzi and D. Rizzatti, 1992. Cases of acute and chronic poisoning after accidental administration of high dose of carbadox in the feed of pigs: Clinical and pathological finding 1992. Selezione Veterinaria, 33: 833-843.

Sogbe, E.J., V. Utrera, E. Ascanio and E.J. Sogbe, 1994. Intoxication by carbadox, effects of the simultaneous medication with furazolidone. Clinical and pathological aspects. Proceedings of the 13th International Pig Veterinary Society Congress, June 26-30, Bangkok, Thailand, pp: 362-582.

Straw, B.E., S. Allaire, W.L. Mengeling and D.J. Taylor, 1999. Diseases of Swine. 8TH Edn., Iowa State Press, Ames, Iowa, ISBN: 08-138-338-1, pp: 590-591.

Thrasher, G.W., J.E. Shively, C.E. Askelson, W.E. Babcock and R.R. Chalquest, 1969. Effects of feeding carbadox upon the growth and performance of young pigs 1969. J. Anim. Sci., 28: 208-215.

Van Der Molen, E.J., M.J.A. Nabuurs and L.P. Jager, 1985. Pathological and clinical changes related to toxicity of carbadox in weaned pigs. Zbl Vet. Med. A., 32: $540-550$.

Yen, J.T., A.H. Jensen, N.H. Bajjalieh and V.D. Lawig, 1976. Effects of methyl-3-(2-Quinoxylinymethylene) carbazate-N1, 7N4-dioxide on nitrogen and energy digestibility and performance of young pigs. J. Anim. Sci., 42: 375-380. 